\title{
How I use transcranial Doppler in the ICU
}

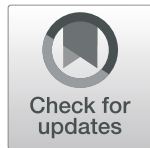

\author{
Chidinma L. Onweni ${ }^{1,2}$, Diane C. McLaughlin ${ }^{1}$ and William D. Freeman ${ }^{1,2,3^{*}}$ (D)
}

We read with great interest the article by Drs. Robba and Taccone [1]. We agree completely with the versatility of transcranial Doppler (TCD) ultrasound in the neurointensive care unit (NeuroICU) population and similarly employ it for its uses for aneurysmal subarachnoid hemorrhage, brain death, and circulatory arrest, and as a noninvasive surrogate for intracranial compliance and elastance [2]. We feel the authors' work is important, especially at a time when TCD seems to be falling out of favor in some NeuroICUs and guidelines. However, we find this ironic, since there is a rise in general critical care ultrasound given its noninvasive utility without ionizing radiation risk compared to computed tomography-based methods of diagnostic evaluation of chest and abdominal body cavities. In our experience, TCD (both blind methods with Spencer ST3 machines, for example) and TCD-imaging methods are useful in the NeuroICU, with 2 major technical caveats: the need for (1) adequate ultrasonographic skills of acquiring imaging and (2) adequate training in interpretation of all features on TCD imaging, including the pulsatility index (i.e., Gosling) and resistance indices (e.g., Pourcelot) [3]. In some cases, teleneurosonology can be performed assuming the 2 caveats above are in place [4]. The most common reason we see for lack of adoption of TCD in intensive care/NeuroICU practice is the lack of these 2 elements. Finally, we note the word "vasospasm" is missing an "s" in Fig. 1, but overall, we commend the authors for their nice summary of TCD use.

\section{Abbreviations}

NeurolCU: Neurointensive care unit; TCD: Transcranial Doppler

\section{Authors' contributions}

CLO, DCM, and WDF contributed to the conception, writing, and critical revision of this letter. All authors read and approved the final manuscript.

\section{Funding}

None

\footnotetext{
* Correspondence: freeman.william1@mayo.edu

This comment refers to the article available at https://doi.org/10.1186/ s13054-019-2700-6.

'Department of Critical Care Medicine, Mayo Clinic, 4500 San Pablo Rd, Jacksonville, FL 32224, USA

2Department of Neurology, Mayo Clinic, 4500 San Pablo Rd, Jacksonville, FL 32224, USA

Full list of author information is available at the end of the article
}

\author{
Availability of data and materials \\ NA
}

Ethics approval and consent to participate

NA

Consent for publication

NA

Competing interests

The authors declare that they have no competing interests.

\section{Author details}

'Department of Critical Care Medicine, Mayo Clinic, 4500 San Pablo Rd, Jacksonville, FL 32224, USA. ²Department of Neurology, Mayo Clinic, 4500 San Pablo Rd, Jacksonville, FL 32224, USA. ${ }^{3}$ Department of Neurologic Surgery, Mayo Clinic, 4500 San Pablo Rd, Jacksonville, FL 32224, USA.

Received: 6 January 2020 Accepted: 26 January 2020

Published online: 05 February 2020

\section{References}

1. Robba C, Taccone FS. How I use transcranial Doppler. Crit Care. 2019;23:420. https://doi.org/10.1186/s13054-019-2700-6.

2. Freeman WD. Management of intracranial pressure. Continuum (Minneap Minn). 2015;21:1299-323.

3. Sierra J, Hanel R, Mooney L, Freeman W. Differential considerations of TCD pulsatility (Gosling's) and resistance (Pourcelot) indices after AVM surgery. J Vasc Interv Neurol. 2014;7:41-3.

4. Rubin MN, Barrett KM, Freeman WD, Lee lannotti JK, Channer DD, Rabinstein AA, Demaerschalk BM. Teleneurosonology: a novel application of transcranial and carotid ultrasound. J Stroke Cerebrovasc Dis. 2015;24:562-5.

\section{Publisher's Note}

Springer Nature remains neutral with regard to jurisdictional claims in published maps and institutional affiliations.

(c) The Author(s). 2020 Open Access This article is distributed under the terms of the Creative Commons Attribution 4.0 International License (http://creativecommons.org/licenses/by/4.0/), which permits unrestricted use, distribution, and reproduction in any medium, provided you give appropriate credit to the original author(s) and the source, provide a link to the Creative Commons license, and indicate if changes were made. The Creative Commons Public Domain Dedication waiver (http://creativecommons.org/publicdomain/zero/1.0/) applies to the data made available in this article, unless otherwise stated. 